\title{
Antitumor effects of matrine on cancer stem like cells isolated from the human liver cancer SMMC-7721 cell line
}

\author{
YONG WANG ${ }^{*}$, YAHUI LIU* ${ }^{*}$ JIANSHUAI JIANG and HANBIN CUI \\ Key Lab of Ningbo, Ningbo First Hospital, Ningbo, Zhejiang 315010, P.R. China \\ Received February 1, 2016; Accepted February 28, 2017
}

DOI: 10.3892/ol.2017.7531

\begin{abstract}
The existence of cancer stem cells (CSCs) or cancer stem-like cells (CSLCs) is regarded as the cause of tumor formation and recurrence. Matrine has been reported to exhibit antitumor effects in cancer cells. In the present study, a preliminary study was performed on the mechanisms of matrine on hepatocellular carcinoma (HCC) stem-like cells. The HCC SMMC-7721 cell line was cultured in tumor stem cell-specific medium to form spheres, and different concentrations $(1,2$ and $5 \mathrm{mg} / \mathrm{kg}$ ) of cisplatin were then used in order to purify the most drug-resistant cells, which were used as CSLCs. An MTT assay was performed to detect the inhibitory effects of matrine against CSLC proliferation. Quantitative polymerase chain reaction (qPCR) and western blot analysis were used to detect changes in cell adhesion regulating gene (CAR), E-cadherin, laminin and fibronectin. As a result, using tryptose sulfite cycloserine medium culture and cisplatin-resistance screening, CSLCs were successfully isolated from the SMMC-7721 cell line. Matrine inhibited the proliferation of CSLCs in vitro. The results of qPCR and western blot analysis demonstrated that matrine upregulated the expression of CAR, E-cadherin, laminin and fibronectin in CSLCs compared with the control treatment. A certain concentration of matrine exhibited antitumor effects on HCC stem like cells.
\end{abstract}

\section{Introduction}

Current evidence demonstrates that cancer stem cells (CSCs) or cancer stem like cells (CSLCs) are present in tumors (1). In 1994, Lapidot et al (2) isolated and identified tumor stem cells from acute myeloid leukemia for the first time. Since then, an increasing number of studies have demonstrated

Correspondence to: Professor Yong Wang, Key Lab of Ningbo, Ningbo First Hospital, 59 Liuting Street, Ningbo, Zhejiang 315010, P.R. China

E-mail: 702820686@qq.com

*Contributed equally

Key words: hepatocellular carcinoma, stem cell, matrine, antitumor effects that CSLCs are present in breast cancer and other common tumors (3-5). Only a small fraction of original cells that are maintained in tumor progression, metastasis and recurrence are capable of self-renewal and multi-differentiation into tumor cells (6-9). Stem cells can proliferate to form suspension sphere cell clones when cultured in low adhesion culture vessels supplemented with epidermal growth factor (EGF) and other growth factors (10). Thus, such sphere-formation cells have been widely used in the isolation and identification of CSCs. Various therapeutic measures are not effective for CSCs, which may be the main reason for the failure of clinical treatment and tumor recurrence.

Matrine, as an alkaloid, has a wide spectrum of biological activities including immune regulation (11), antifibrosis (12) and antiviral activity (13). Previous studies have shown that matrine may be used as one type of antitumor drug for leukemia and lung, liver, gastric, breast and cervical cancers, as well as numerous other types of malignant tumors with high drug resistant activity $(14,15)$. The present study confirmed that certain concentrations of matrine could significantly inhibit the proliferation and invasion of the human hepatocellular carcinoma (HCC) cell line $(16,17)$. However, to the best of our knowledge, the effect and mechanism of matrine on hepatic cancer stem cells in vitro has not yet been reported.

In the present study, CSLCs were isolated and purified from a human liver cancer cell line, and the positive antitumor effects of matrine were observed. Furthermore, the associated mechanism was studied in vitro.

\section{Materials and methods}

Materials. The human liver cancer SMMC-7721 cell line was purchased from American Type Culture Collection (Manassas, VA, USA). BALB/c nude mice (40 males, aged between 4 and 6 weeks and weighing between 16 and $18 \mathrm{~g}$ ) were purchased from Shanghai Experimental Animal Center of Chinese Academy of Sciences (Shanghai, China). The nude mice were caged individually under specific-pathogen free conditions in the Laboratory Animal Research Center of Ningbo University at a temperature of $22 \pm 2^{\circ} \mathrm{C}$, a relative humidity between 40 and $60 \%$ and artificially illuminated on an $\sim 12$-h light/dark cycle. The air exchange rate was about 18 times/h. All of the nude mice were provided with sterilized normal pellet food and sterile water ad libitum. The Ningbo University Experimental Animal Care Commission approved the experimental protocol. 
Dulbecco's modified Eagle's medium (DMEM), fetal bovine serum, epidermal growth factor (EGF), basic fibroblast growth factor (bFGF), noggin, cisplatin, Verso 1-Step RT-PCR kit was purchased from Thermo Fisher Scientific, Inc. (Waltham, MA, USA). The fluorescence microscope (magnification, x100) and digital image photographic system were Leica products (Leica Microsystems, Inc., Buffalo Grove, IL, USA).

Hepatoma stem like cell enrichment and cultivation. The human hepatocellular carcinoma SMMC-7721 cell line was cultured in DMEM containing $10 \%$ fetal bovine serum at $37^{\circ} \mathrm{C}$ in a $5 \% \mathrm{CO}_{2}$ atmosphere. At the logarithmic growth phase, cells were harvested, resuspended in tumor stem cell enrichment medium (DMEM serum-free culture medium $+10 \mathrm{ng} / \mathrm{ml}$ $\mathrm{EGF}+10 \mathrm{ng} / \mathrm{ml} \mathrm{bFGF}+10 \mathrm{ng} / \mathrm{ml}$ noggin $+1,000 \mu / \mathrm{ml} \mathrm{leukemia}$ inhibitory factor) and then plated into polyhydroxy ehtyl methacrylate pretreatment flasks for two weeks. Subsequent to the formation of clones, cells were digested, centrifuged $(1,000 \mathrm{x} \mathrm{g}$ for $10 \mathrm{~min})$ at $4^{\circ} \mathrm{C}$ and resuspended in PBS. The cell suspension $\left(\sim 5 \times 10^{5}\right.$ cells) was inoculated into the back of nude mice to form a solid tumor. After two weeks, 1,2 and $5 \mathrm{mg} / \mathrm{kg}$ of cisplatin was injected into mice to select the strongest resistance of tumor stem cells. Subsequently, the tumor tissue within the most notable effects of cisplatin intervention was irrigated, trimmed, cut broken, repeatedly digested into single cells and then cultured in tryptose sulfite cycloserine (TSC) medium at $37^{\circ} \mathrm{C}$ in a $5 \% \mathrm{CO}_{2}$ atmosphere. During this time period, the adherent cells were continually discarded. The suspended cells were continuously collected, repeatedly triturated into a single cell suspension and reinoculated in TSC medium.

Immunofluorescence microscopy. The expression of CD24 was firstly analyzed using immunofluorescence microscopy. Liver CSC clones from the SMMC-7721 cell line were digested into single cells with trypsin (Sigma-Aldrich; Merck KGaA, Darmstadt, Germany) and incubated in a blocking solution consisting of $10 \%$ normal fetal bovine serum and $0.1 \%$ Triton $\mathrm{X}-100$ (Sigma-Aldrich; Merck KGaA) in $0.1 \mathrm{M}$ PBS for $1 \mathrm{~h}$ at room temperature. Then, rat anti-human CD24 (cat. no. 563545; dilution, 1:1,000; BD Pharmingen; BD Biosciences, Franklin Lakes, NJ, USA) were added to the cells and incubated at room temperature for $1 \mathrm{~h}$. FITC-conjugated anti-rat IgM monoclonal antibody (cat. no. 553887; dilution, 1:500; BD Pharmingen; BD Biosciences) were applied at $4^{\circ} \mathrm{C}$ overnight for visualization. Following antibody staining, cells were fixed with $2 \%$ paraformaldehyde at room temperature for $15 \mathrm{~min}$ and mounted with DAPI-fluoromount-G (SouthernBiotech, Birmingham, AL, USA). Fluorescent micrographs were obtained using Leica DM IL LED inverted fluorescent microscope (magnification, x100; Leica Microsystems, Inc.).

Cell viability assay. MTT (Sigma-Aldrich; Merck KGaA) was applied to evaluate the effects on proliferation and viability of liver stem cells. Liver CSC clones were digested into single cells and plated in triplicate at 5,000 cells per well onto 96-well plates, and cultured with different concentrations of matrine $(0,5,25,50,100$ and $200 \mu \mathrm{g} / \mathrm{ml})$. Following incubation for $72 \mathrm{~h}, 10 \mu \mathrm{l}$ of MTT solution $(5 \mu \mathrm{g} / \mathrm{ml})$ was added to each well. The plates were then incubated for $4 \mathrm{~h}$ at $37^{\circ} \mathrm{C}$. Intracellular formazan crystals were dissolved by the addition of $100 \mu \mathrm{l}$ of isopropanol-hydrochloric acid-sodium dodecyl sulfate solution $(10 \%)$ to each well. Following overnight incubation at $37^{\circ} \mathrm{C}$, the optical density of the samples was determined at $570 \mathrm{~nm}$. Rate of inhibition was calculated using the equation: Cell inhibition rate $(\%)=($ treated group-control group)/control group x100.

Reverse transcription-quantitative polymerase chain reaction $(R T-q P C R)$. The total RNA of hepatocellular carcinoma SMMC-7721 cells (SMMC-7721), hepatocellular carcinoma stem cell SMMC-7721-sphere (SMMC-7721-sphere) and hepatocellular carcinoma stem cell SMMC-7721-sphere with $50 \mu \mathrm{g} / \mathrm{ml}$ matrine treatment (SMMC-7721-sphere-Matrine) were extracted using the TRIzol ${ }^{\circledR}$ Reagent (Invitrogen; Thermo Fisher Scientific, Inc.) Reverse transcription was performed using $2 \mu \mathrm{g}$ of total RNA, according to the manufacturer's protocol for Verso 1-Step RT-PCR kit's (Thermo Fisher Scientific, Inc.). Surface marker expression of octamer-binding transcription factor-4 (OCT-4), NANOG, Notch, cluster of differentiation (CD)133, CD24, sex determining region Y-box-2 (SOX-2) and CD90 in tumor stem-like cells was detected using RT-qPCR. Furthermore, the association between mRNA levels of CAR, E-cadherin, laminin and fibronectin and cell invasion and metastasis was also determined. $\beta$-actin was used as an internal control. The primers used for amplification are shown in Table I.

Western blot analysis. Collected cells were lysed immediately in RIPA buffer (150 mM NaCl, $50 \mathrm{mM}$ Tris, $1 \%$ NP-40, $0.5 \%$ sodium deoxycholate, $0.1 \%$ SDS, $\mathrm{pH}$ 7.4), supplemented with protease inhibitor cocktail (Roche Diagnostics, Basel, Switzerland), Protein concentration was determined using the Micro BCA kit (Pierce; Thermo Fisher Scientific, Inc.). Equal amounts of protein $(60 \mu \mathrm{g})$ were boiled for $5 \mathrm{~min}$, separated by SDS-PAGE and electro-blotted to a nitrocellulose membrane. Following blocking, the blots were incubated with an appropriate dilution of specific rabbit antibodies against E-cadherin (catalog no.3195S; dilution, 1:1,000; Cell Signaling Technology Inc., Dnavers, MA, USA), laminin (catalog no. ab11575; dilution, 1:1,000; Abcam, Cambridge, UK), fibronectin (catalog no. ab2413; dilution, 1:1,000; Abcam) for $1 \mathrm{~h}$ at room temperature. The blots were washed by TBST reagent $(50 \mathrm{mM}$ Tris, $\mathrm{pH} 7.4,150 \mathrm{mM} \mathrm{NaCl}, 0.05 \%$ Tween-20) three times and then incubated with a 1:2,000 dilution of horseradish peroxidase-conjugated secondary antibody (catalog no. sc-2492; Santa Cruz Biotechnology, Inc., Dallas, TX, USA) for $1 \mathrm{~h}$ at room temperature. The blots were washed three times and then developed using a chemiluminescence assay. Finally, $\beta$-actin (Cell Signaling Technology, Inc., Danvers, MA, USA) was used as a loading control.

Statistical processing. Statistical analysis was performed using SPSS 16.0 (SPSS, Inc., Chicago, IL, USA). All measurement data was analyzed by one-way analysis of variance test, followed by Tukey's test. For data without a normal distribution, Wilcoxon test were used to analyze the difference between the same cell groups exposed to different treatments. $\mathrm{P}<0.05$ was considered to indicate a statistically significant difference. Dose-dependent associations were determined by multiple linear regressions. All experiments were repeated at least twice (with duplicate assays). 
Table I. PCR amplification primers.

\begin{tabular}{|c|c|}
\hline Genes & Primers \\
\hline \multirow[t]{2}{*}{ OCT-4 } & F: 5'-CTGGGTTGATCCTCGGACCT-3' \\
\hline & R: 5'-CCATCGGAGTTGCTCTCCA-3' \\
\hline \multirow[t]{2}{*}{ NANOG } & F: 5'-TTTGTGGGCCTGAAGAAAACT-3' \\
\hline & R: 5'-AGGGCTGTCCTGAATAAGCAG-3' \\
\hline \multirow[t]{2}{*}{ Notch } & F: 5'-GCACTTTCTGTGAGGAGGACAT-3' \\
\hline & R: 5'-AGCAGGAGCTCTCTGTGCAGT-3' \\
\hline \multirow[t]{2}{*}{ CD133 } & F: 5'-TCGGAAACTGGCAGATAGCAA-3' \\
\hline & R: 5'-GTGAACGCCTTGTCCT-3' \\
\hline \multirow[t]{2}{*}{ CD24 } & F:5'-TTTGACTAGATGATGAATGCCAAT-3' \\
\hline & R: 5'-GGATGTTGCCTCTCCTTCAT-3' \\
\hline \multirow[t]{2}{*}{ SOX-2 } & F: 5'-AAGAGAACACCAATCCCATCCA-3' \\
\hline & R: 5'-AGTCCCCCAAAAAGAAGTCCA-3' \\
\hline \multirow[t]{2}{*}{ CD90 } & F: 5'-GTTAGGCTGGTCACCTTCTG-3' \\
\hline & R: 5'-GAGATCCCAGAACCATGAACC-3' \\
\hline \multirow[t]{2}{*}{ CAR } & F: 5'-TGTTCATGCCGACGCTTGCA-3' \\
\hline & R: 5'-TTCCAACTACACAGTTTATT-3' \\
\hline \multirow[t]{2}{*}{ E-cadherin } & F: 5'-GGTCTCCTCATGGCTTTGCC-3' \\
\hline & R: 5'-CACAGTTCTCAAAGCACAGCG-3' \\
\hline \multirow[t]{2}{*}{ Laminin } & F: 5'-CAGGCCCGCAAACAAGCAGC-3' \\
\hline & R: 5'-TCCAAGCGTGTGGACCCGGA-3' \\
\hline \multirow[t]{2}{*}{ Fibronectin } & F: 5'-GCCGCCACGTGCCAGGATTA-3' \\
\hline & R: 5'-ACCAGTTGGGGAAGCTCGTCTG-3' \\
\hline \multirow[t]{2}{*}{$\beta$-actin } & F: 5'-CTGTCTGGCGGCACCACCAT-3' \\
\hline & R: 5'-GCAACTAAGTCATAGTCCGC-3' \\
\hline
\end{tabular}

F, forward; R, reverse; $\mathrm{CD}$, cluster of differentiation; SOX-2, sex determining region Y-box 2; OCT-4, octamer binding transcription factor-4; CAR, cell adhesion regulating gene.
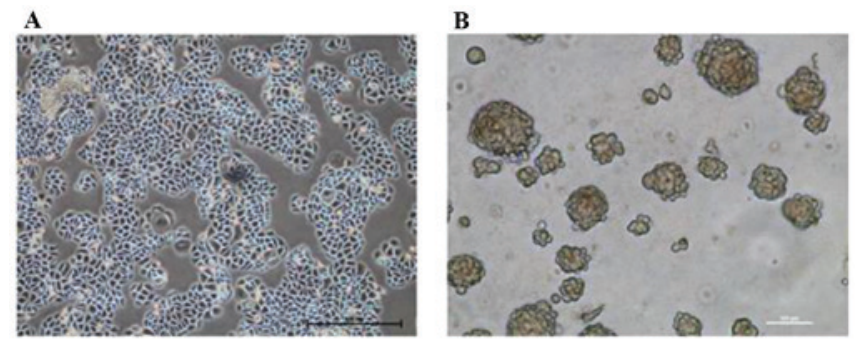

Figure 1. SMMC-7721 cells cultured in TSC medium formed clones after two weeks. (A) SMMC-7721 cells cultured in Dulbecco's modified Eagle's medium. (B) Following transfer to TSC medium for two weeks, cell spheres were formed. The cell imaging was performed using the Leica DM IL LED microscope (magnification, x100); scale bar, $20 \mu \mathrm{m}$. TSC, tryptose sulfite cycloserine.

\section{Results}

CSLC clone formation of the SMMC-7721 cell line is induced by chemotherapeutic drug resistance screening. Morphological observation revealed that the cultured SMMC-7721 cells possessed the typical characteristics of epithelial cells, and adhered to the bottom of the dish in a monolayer (Fig. 1A). Following TSC medium suspension

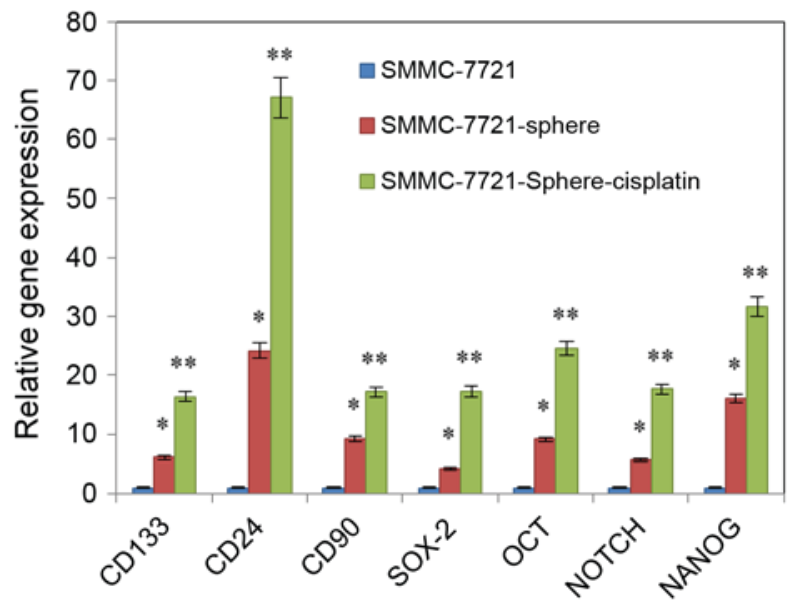

Figure 2. Cancer stem cell specific markers were highly expressed in SMMC-7721-sphere and SMMC-7721-sphere-cisplatin cells isolated and purified from the SMMC-7721 cell line. ${ }^{*} \mathrm{P}<0.05 ;{ }^{* *} \mathrm{P}<0.01$. CD, cluster of differentiation; SOX-2, sex determining region Y-box-2; OCT-4, octamer binding transcription factor- 4 .

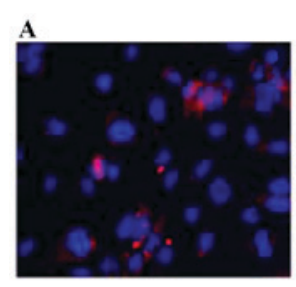

SMMC-7721-sphere

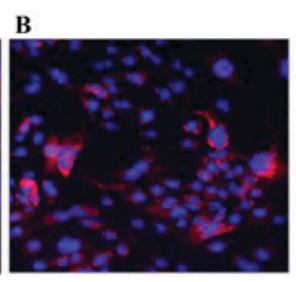

SMMC-7721-sphere-cisplatin

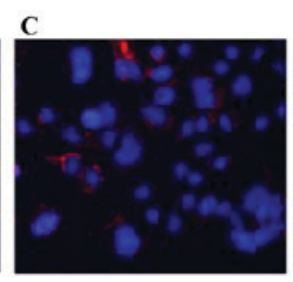

SMMC-7721
Figure 3. Comparison of CD24 expression in (A) SMMC-7721-sphere, (B) SMMC-7721-sphere-cisplatin and (C) and SMMC-7721, identified using immunofluorescence. The nucleus was stained with DAPI (blue). CD24 expression examined by primary antibodies followed by fluorescein isothiocyanate-conjugated secondary antibodies (red). Fluorescent micrographs were obtained using the Leica DM IL LED inverted fluorescent microscope (magnification, x100). CD, cluster of differentiation.

culture for two weeks, SMMC-7721-sphere cell clones were formed (Fig. 1B) and transplanted into nude mice to generate xenogeneic tumors. After two weeks, cisplatin was selected to interfere with the proliferation of the tumor. The results suggested that cisplatin treatments inhibited tumor growth in a time and dose-dependent manner; among them, $5 \mathrm{mg} / \mathrm{kg}$ of cisplatin treatment exhibited the most drug resistance. Following intervention for 18 days, the cells of the $5 \mathrm{mg} / \mathrm{kg}$ cisplatin group were isolated, digested and cultured in TSC medium for another two weeks until the new cell clones were reformed. These SMMC-7721-sphere-cisplatin cell clones had CSLC characteristics, including amplification ability, strong tumorigenesis ability in vivo and resistance to chemotherapy (Table II).

Different types of stem cell markers were expressed in the obtained stem-like cell clones. qPCR revealed that the expression levels of NANOG, SOX-2, OCT-4, Notch, CD24, CD90 and $C D 133$ were upregulated in SMMC-7721-sphere-cisplatin as compared with SMMC-7721 and SMMC-7721-sphere. Among them, expression of CD24 was the most increased (Fig. 2; $\mathrm{P}<0.01$ ). Fig. 3 also showed that CD24 was highly 
Table II. Tumor size in nude mice inoculated with different concentrations of cisplatin $\left(\mathrm{mm}^{2}\right)$.

\begin{tabular}{crrrr}
\hline Time, days & Control & $1 \mathrm{mg} / \mathrm{kg}$ & $2 \mathrm{mg} / \mathrm{kg}$ & $5 \mathrm{mg} / \mathrm{kg}$ \\
\hline 3 & $520.20 \pm 3.36$ & $519.70 \pm 5.21$ & $517.90 \pm 7.08$ & $510.30 \pm 6.09^{\mathrm{b}}$ \\
6 & $699.90 \pm 5.53$ & $650.20 \pm 5.71$ & $599.90 \pm 5.61^{\mathrm{a}}$ & $529.90 \pm 5.72^{\mathrm{b}}$ \\
9 & $1,000.00 \pm 6.99$ & $971.10 \pm 6.67$ & $739.80 \pm 5.77^{\mathrm{a}}$ & $560.20 \pm 5.71^{\mathrm{b}}$ \\
12 & $1,502.00 \pm 10.09$ & $1,299.10 \pm 7.37$ & $799.30 \pm 5.30^{\mathrm{a}}$ & $529.80 \pm 5.14^{\mathrm{b}}$ \\
15 & $1,601.00 \pm 8.39$ & $1,502.30 \pm 6.42$ & $829.60 \pm 4.55^{\mathrm{a}}$ & $520.20 \pm 3.35^{\mathrm{b}}$ \\
18 & $1,700.50 \pm 8.24$ & $1,600.90 \pm 8.53$ & $799.50 \pm 5.40^{\mathrm{a}}$ & $499.90 \pm 6.72^{\mathrm{b}}$ \\
\hline
\end{tabular}

${ }^{\mathrm{a}} \mathrm{P}<0.05 ;{ }^{\text {b }} \mathrm{P}<0.01$.

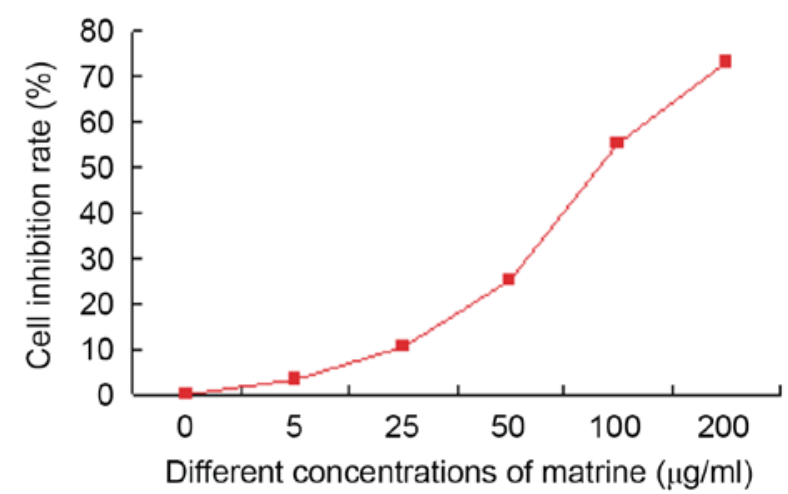

Figure 4. Matrine inhibited the proliferation of liver stem like cells purified from the SMMC-7721 cell line in a dose-dependent manner.

expressed in SMMC-7721-sphere-cisplatin compared with SMMC-7721 and SMMC-7721-sphere (Fig. 3).

Matrine inhibits the proliferation of liver CSLCs in a dose-dependent manner. MTT results revealed that matrine inhibited the growth of liver cancer stem cells in vitro. Matrine $(5 \mu \mathrm{g} / \mathrm{ml})$ showed little effect (inhibition rate only $3.0 \% \pm 0.3 \%)$. The inhibition rate of $100 \mu \mathrm{g} / \mathrm{ml}$ matrine was $>50 \%(55.1 \% \pm 0.6 \%)$. In addition, the cytotoxic effect of $200 \mu \mathrm{g} / \mathrm{ml}$ matrine on liver cancer stem cells was observed at $72 \mathrm{~h}$ with an inhibition rate of $77.4 \% \pm 0.8 \%$. On the basis of the aforementioned results, $50 \mu \mathrm{g} / \mathrm{ml}$ of matrine was selected for the subsequent experiments (Fig. 4).

Matrine induces the expression of CAR, E-cadherin, laminin and fibronectin in liver CSLCs. To explore the mechanisms underlying matrine-induced apoptosis, the expression of CAR, E-cadherin, laminin and fibronectin was detected by RT-qPCR. As shown in Fig. 5, the mRNA levels of CAR, laminin, E-cadherin and fibronectin in SMMC-7721-sphere cells were lower than SMMC-7721 cells. However, following matrine treatment, the mRNA levels of these genes were significantly increased by $15.2,8.5,4.9$ and 6.3 times, respectively $(\mathrm{P}<0.05)$.

Furthermore, western blot analysis results (Fig. 6) also demonstrated that the expression of laminin, fibronectin and E-cadherin protein in SMMC-7721-sphere cells was lower than in SMMC-7721 cells after $72 \mathrm{~h}$. Matrine $(50 \mu \mathrm{g} / \mathrm{ml})$

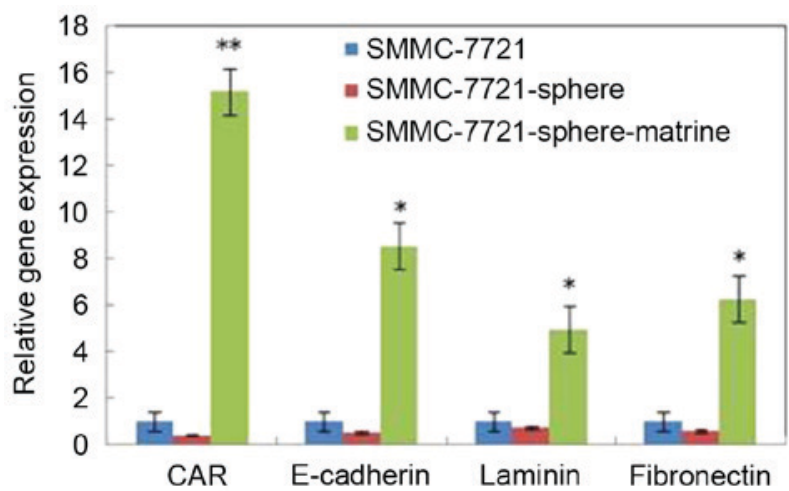

Figure 5. Matrine induced the expression of CAR, E-cadherin, laminin and fibronectin in liver stem like cells (SMMC-7721-sphere-matrine) compared with the SMMC-7721 cell line. ${ }^{*} \mathrm{P}<0.05 ;{ }^{* *} \mathrm{P}<0.01$. CAR, cell adhesion regulating gene.

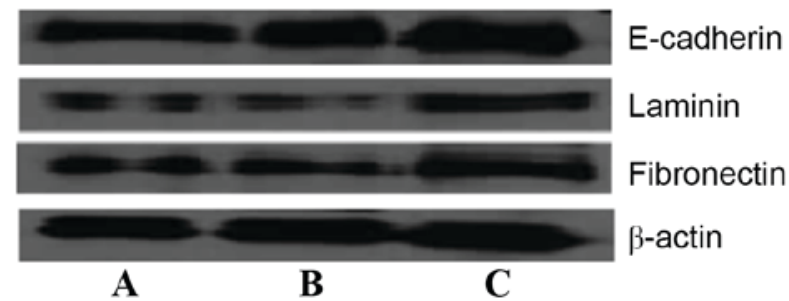

Figure 6. Western blot analysis of the expression of E-cadherin, laminin and fibronectin in different cell lines following matrine treatment for $72 \mathrm{~h}$ : (A) SMMC-7721; (B) SMMC-7721-sphere; and (C) SMMC-7721-sphere-matrine.

significantly induced the expression of these proteins, which was consistent with the aforementioned results $(\mathrm{P}<0.05)$.

\section{Discussion}

For decades, matrine, as a traditional Chinese herbal medicine, has proved to possess cytoprotective effects and biological safety, which has been used for a number of treatments, including hepatic fibrosis, atherosclerosis, arrhythmias and infectious diseases $(18,19)$. Previous studies have suggested that matrine may eliminate tumor cells by apoptosis induction (20,21). Ma et al (22) demonstrated that matrine significantly inhibited the invasion of human pancreatic cancer cells by downregulating the expression of membrane type 
1-matrix metalloproteinase. However, previous studies mainly focused on the antitumor effects of matrine on common tumor cells. Based on the theory of CSCs, the malignant degree of tumors is mainly determined by the proportion of CSCs. Common cancer cells may be eliminated through various treatments. Due to possessing a strong drug tolerance, CSCs are not easily destroyed, which leads to the failure of treatment. Therefore, a key goal for tumor therapy is to effectively induce the apoptosis of tumor stem cells (23).

In the present study, tumor stem-like cells were isolated and purified from the human HCC SMMC-7721 cell line, which overexpresses the tumor stem cell specific marker CD24 (24-26). MTT results suggested that different concentrations $(25,50$, 100 and $200 \mu \mathrm{g} / \mathrm{ml}$ ) of matrine may inhibit the proliferation of stem like cells in vitro. In addition, the malignancy of the tumor is not only determined by the ability of proliferation, but is also associated with the invasion and metastasis of tumor cells. Therefore, it is necessary to evaluate the effect of matrine on tumor cell invasion and metastasis. Previous studies demonstrated that the high expression of E-cadherin, laminin and fibronectin also proved to be positively associated with tumor recurrence and metastasis (27-30). Therefore, laminin, fibronectin and E-cadherin were selected to evaluate the mechanism of matrine on the invasion and metastasis in the SMMC-7721 cell line. The results demonstrated that the expression of laminin, fibronectin and E-cadherin in CSLCs was decreased compared with common liver cancer cells. However, $50 \mu \mathrm{g} / \mathrm{ml}$ matrine could significantly induce the expression of laminin $(\mathrm{P}<0.05)$, fibronectin $(\mathrm{P}<0.05)$ and $\mathrm{E}$-cadherin $(\mathrm{P}<0.05)$, which indicated that matrine could reduce the adhesion ability of HCC cells, thereby inducing the apoptosis of liver CSLCs in vitro.

CAR performs a role in the process of tumor recurrence and metastasis. Yamamoto et al detected 30 patients with primary hepatic carcinoma and identified that CAR mRNA level was significantly depressed in HCC tissues compared with the adjacent tissue (31). The present study also showed that the mRNA level of CAR was markedly increased by matrine treatment, which suggested that matrine exerted antitumor effects through the regulation of the CAR signal transduction pathway. The results of the present study demonstrated that matrine exhibited preferential anti-tumor effects against hepatocellular carcinoma stem cells. Therefore, it may be a therapeutic agent for HCC treatment in the future.

\section{Acknowledgements}

The present study was supported by Ningbo Medical Project Foundation (grant no. 2011B05) and the Major Science and Technology Planning Program of Ningbo (grant no. 2012C5013).

\section{References}

1. Reya T, Morrison SJ, Clarke MF and Weissman IL: Stem cells, cancer, and cancer stem cells. Nature 414: 105-111, 2001.

2. Lapidot T, Sirard C, Vormoor J, Murdoch B, Hoang T, Caceres-Cortes J, Minden M, Paterson B, Caligiuri MA and Dick JE: A cell initiating human acute myeloid leukaemia after transplantation into SCID mice. Nature 367: 645-648, 1994.

3. Al-Hajj M, Wicha MS, Benito-Hernandez A, Morrison SJ and Clarke MF: Prospective identification of tumorigenic breast cancer cells. Proc Natl Acad Sci USA 100: 3983-3988, 2003.
4. Singh SK, Clarke ID, Hide T and Dirks PB: Cancer stem cells in nervous system tumors. Oncogene 23: 7267-7273, 2004.

5. Wang X, Kruithof-de Julio M, Economides KD, Walker D, Yu H, Halili MV, Hu YP, Price SM, Abate-Shen C and Shen MM: A luminal epithelial stem cell is a cell of origin for prostate cancer. Nature 461: 495-500, 2009.

6. Clarke MF, Dick JE, Dirks PB, Eaves CJ, Jamieson $\mathrm{CH}$, Jones DL, Visvader J, Weissman IL and Wahl GM: Cancer stem cells--perspectives on current status and future directions: AACR workshop on cancer stem cells. Cancer Res 66: 9339-9344, 2006.

7. Yang YM and Chang JW: Current status and issues in cancer stem cell study. Cancer Invest 26: 741-755, 2008.

8. Vermeulen L, Todaro M, de Sousa Mello F, Sprick MR, Kemper K Perez Alea M, Richel DJ, Stassi G and Medema JP: Single-cell cloning of colon cancer stem cells reveals a multi-lineage differentiation capacity. Proc Natl Acad Sci USA 105: 13427-13432, 2008.

9. Jordan CT: Cancer stem cell biology: From leukemia to solid tumors. Curr Opin Cell Biol 16: 708-712, 2004.

10. Uchida S, Yokoo S, Yanagi Y, Usui T, Yokota C, Mimura T, Araie M, Yamagami S and Amano S: Sphere formation and expression of neural proteins by human corneal stoma cells in vitro. Invest Ophthalmol Vis Sci 46: 1620-1625, 2005.

11. Zhu L, Pan QX, Zhang XJ, Xu YM, Chu YJ, Liu N, Lv P, Zhang GX and Kan QC: Protective effects of matrine on experimental autoimmune encephalomyelitis via regulation of ProNGF and NGF signaling. Exp Mol Pathol 100: 337-343. 2016.

12. Chen JX, Shen HH, Niu M, Guo YM, Liu XQ, Han YZ, Zhang YM, Zhao YL, Bai BK, Zhou WJ and Xiao XH: Anti-hepatitis B virus effect of matrine-type alkaloid and involvement of p38 mitogen-activated protein kinase and tumor necrosis factor receptor-associated factor 6 . Virus Res 215: 104-113, 2016.

13. Zhang JP, Zhang M, Zhou JP, Liu FT, Zhou B, Xie WF and Guo C: Antifibrotic effects of matrine on in vitro and in vivo models of liver fibrosis in rats. Acta Pharmacol Sin 22: 183-186, 2001.

14. Liu Y, Xu Y, Ji W, Li X, Sun B, Gao Q and Su C: Anti-tumor activities of matrine and oxymatrine: Literature review. Tumor Biol 35: 5111-5119, 2014.

15. Liao H, Zhao X, Qu J, Zhang J and Cai H: Matrine suppresses invasion and metastasis of NCI-H1299 cells by enhancing microRNA-133a expression. Int J Clin Exp Med 8: 10714-10722, 2015.

16. Qian L, Liu Y, Xu Y, Ji W, Wu Q, Liu Y, Gao Q and Su C: Matrine derivative WM130 inhibits hepatocellular carcinoma by suppressing EGFR/ERK/MMP-2 and PTEN/AKT signaling pathways. Cancer Lett 368: 126-134, 2015.

17. Yang N, Han F, Cui H, Huang J, Wang T, Zhou Y and Zhou J: Matrine suppresses proliferation and induces apoptosis in human cholangiocarcinoma cells through suppression of JAK2/STAT3 signaling. Pharmacol Rep 67: 388-393, 2015.

18. Gao HY, Li GY, Lou MM, Li XY, Wei XY and Wang JH: Hepatoprotective effect of Matrine salvianolic acid B salt on carbon tetrachloride-induced hepatic fibrosis. J Inflamm 9: 16, 2012.

19. Xin HB and Liu SF: Effects of matrine on myocardial contraction and arrhythmia in isolated heart atria. Zhongguo Yao Li Xue Bao 8: 501-505, 1987 (In Chinese).

20. Wang HQ, Jin JJ and Wang J: Matrine induces mitochondrial apoptosis in cisplatin-resistant non-small cell lung cancer cells via suppression of $\beta$-catenin/survivin signaling. Oncol Rep 33: 2561-2566, 2015.

21. Yang N, Han F, Cui H, Huang J, Wang T, Zhou Y and Zhou J: Matrine suppresses proliferation and induces apoptosis in human cholangiocarcinoma cells through suppression of JAK2/STAT3 signaling. Pharmacol Rep 67: 388-393, 2015.

22. Ma Y, Zou F, Xiong J, Wan W, Yin L, Li X, Bei Z, Yuan L, Meng S, Wang J and Song G: Effect of Matrine on HPAC cell migration by down-regulating the expression of MT1-MMP via Wnt signaling. Cancer Cell Int 15: 59, 2015.

23. Gilbert CA and Ross AH: Cancer stem cells: Cell culture, markers and targets for new therapies. J Cell Biochem 108: 1031-1038, 2009.

24. Ke J, Wu X, Wu X, He X, Lian L, Zou Y, He X, Wang H, Luo Y, Wang L and Lan P: A subpopulation of CD24+ cells in colon cancer cell lines posse stem cell characteristics. Neoplasma 59: 282-288, 2012 
25. Smith SC, Oxford G, Wu Z, Nitz MD, Conaway M, Frierson HF, Hampton $\mathrm{G}$ and Theodorescu D: The metastasis-associated gene CD24 is regulated by Ral GTPase and is a mediator of cell proliferation and survival in human cancer. Cancer Res 66: 1917-1922, 2006.

26. Zhang Y, Wei J, Wang H, Xue X, An Y, Tang D, Yuan Z, Wang F, Wu J, Zhang J and Miao Y: Epithelial mesenchymal transition correlates with CD24+CD44+ and CD133+ cells in pancreatic cancer. Oncology Rep 27: 1599-1605, 2012.

27. Inayoshi J, Iehida T, Sugitani S, Tsuboi Y, Genda T, Honma N and Asakura H: Gross appearance of hepatocellular careinoma reflects E-cadherin expression and risk of early recurrence after surgical treatment. J Gastroen Hepatol 18: 673-677, 2003.

28. Masaki T, Sugiyama M, Matsuoka H, Abe N, Izumisato Y, Sakamoto A and Atomi Y: Coexpression of matrilysin and Laminin-5 gamma2 chain may contribute to tumor cell migration in colorectal carcinomas. Dig Dis Sci 48: 1262-1267, 2003.
29. Mohammadizadeh F, Ghasemibasir H, Rajabi P, Naimi A, Eftekhari A and Mesbah A: Correlation of E-cadherin expression and routine immunohistochemistry panel in breast invasive ductal carcinoma. Cancer Biomark 5: 1-18, 2009.

30. Kowalski PJ, Rubin MA and Kleer CG: E-cadherin expression in primary carcinomas of the breast and its distant metastases. Breast Cancer Res 5: R217-R222, 2003.

31. Yamamoto H, Itoh F, Sakamoto H, Nakajima Y, Une Y, Hinoda Y and Imai K: Association of reduced cell adhesion regulator messenger RNA expression with tumor progression in human hepatocellular carcinoma. Int J Cancer 74: 251-254, 1997. 